Banking and Transparency: Is More Information Always Better?

Nicole Allenspach 
The views expressed in this paper are those of the author(s) and do not necessarily represent those of the Swiss National Bank. Working Papers describe research in progress. Their aim is to elicit comments and to further debate.

\section{Copyright ${ }^{\odot}$}

The Swiss National Bank (SNB) respects all third-party rights, in particular rights relating to works protected by copyright (information or data, wordings and depictions, to the extent that these are of an individual character). SNB publications containing a reference to a copyright ( $\odot$ Swiss National Bank/SNB, Zurich/year, or similar) may, under copyright law, only be used (reproduced, used via the internet, etc.) for non-commercial purposes and provided that the source is mentioned. Their use for commercial purposes is only permitted with the prior express consent of the SNB.

General information and data published without reference to a copyright may be used without mentioning the source.

To the extent that the information and data clearly derive from outside sources, the users of such information and data are obliged to respect any existing copyrights and to obtain the right of use from the relevant outside source themselves.

\section{Limitation of liability}

The SNB accepts no responsibility for any information it provides. Under no circumstances will it accept any liability for losses or damage which may result from the use of such information. This limitation of liability applies, in particular, to the topicality, accuracy, validity and availability of the information.

ISSN 1660-7716 (printed version)

ISSN 1660-7724 (online version)

๑ 2009 by Swiss National Bank, Börsenstrasse 15, P.0. Box, CH-8022 Zurich 


\title{
Banking and Transparency: Is More Information Always Better?
}

\author{
Nicole Allenspach ${ }^{* \dagger}$
}

September 2009

\begin{abstract}
This paper shows that transparency in banking can be harmful from a social planner's point of view. According to our model, enhancing transparency above a certain level may lead to the inefficient liquidation of a bank. The reason lies in the nature of a standard deposit contract: its payoff scheme has limited upside gains (cap) but leaves the depositor with the downside risk. Accordingly, depositors will not take into account possible future upside gains of the bank when deciding whether or not to withdraw their deposits. Our result points towards a trade-off the regulator faces: while enhancing transparency may be useful to reduce incentives for excessive risk-taking (moral hazard), it may also increase the risk of inefficient bank runs.
\end{abstract}

Keywords: banking, transparency, financial stability, bank run

${ }^{*}$ I thank Robert Bichsel, Urs Birchler, Jürg Blum, Jeannette Henggeler-Müller, Yvan Lengwiler and Hyun Song Shin for helpful comments and discussions. The author also acknowledges comments and suggestions from an anonymous refree and from seminar participants at the Swiss National Bank and at the INFINITI Conference on International Finance 2008 in Dublin. The opinions expressed herein are my own and not those of the Swiss National Bank.

${ }^{\dagger}$ Swiss National Bank. E-mail: nicole.allenspach@snb.ch. 


\section{Introduction}

Since the Asian crisis in 1998, calls for enhancing transparency in the banking sector have been prompted regularly. The outburst of the subprime mortgage crisis in mid2007 has reignited an interest in transparency as some banks have been severly criticized for not disclosing all relevant information. Accordingly, one of the lessons often drawn from this crisis is that banks have to become more transparent to the markets. ${ }^{1}$ In other words, transparency is generally regarded as being beneficial in enhancing both the efficiency and the stability of banks and a financial system as a whole.

However, the actual impact of enhancing transparency may be less evident in the case of banks. Banks do in fact exist because of inefficiencies. They solve the information asymmetry between lenders and borrowers and are therefore opaque by definition. Hence, due to the existence of market distortions, disclosing information ${ }^{2}$ to the market may be less beneficial as often claimed or may - under certain circumstances - even worsen the overall outcome. ${ }^{3}$ Furman and Stiglitz (1998) argue that greater transparency could have severly aggravated the savings and loans crisis in the United States as many banks would have had to shut down, cut their lending to a significant extent or receive substantial equity injections. Similarly, De Grauwe (2008) points out that transparency is not a panacea to prevent financial crises and may sometimes even be counterproductive.

The aim of this paper is to contribute to the discussion on transparency in banking by pointing out a possible drawback of information disclosure to the market. It is thereby important to note that the paper does not intend to carry out a balanced analysis of possibly beneficial and harmful effects of transparency but rather to provide an example where being transparent might not always be optimal. In a simple model where the bank's investment portfolio is solely exposed to exogenous risk factors such as macroeconomic shocks or a stock market crash, we show that enhancing transparency over a certain level may lead to the inefficient liquidation of a bank. The basic idea behind this is as follows: A bank may temporarily be threatened by a shock but the institution's overall outlook is still positive. Disclosing information on that bank while

\footnotetext{
${ }^{1}$ See, e.g., Financial Stability Forum (2008).

${ }^{2}$ Disclosing information does not necessarily imply transparency as, e.g., it does not automatically ensure that the information disclosed is also received and correctly understood by the market. Nevertheless, in what follows, these expressions are used interchangeably.

${ }^{3}$ According to the theory of the second best: When there is more than one imperfection in an economy, removing one of them need not improve welfare.
} 
in trouble may lead depositors to run a bank with a positive net present value. At this stage, allowing for some degree of intransparency - or in some cases even complete intransparency - may keep depositors from running the bank and may thus prevent the inefficient liquidation of this bank.

The reason for this inefficient liquidation lies in the very nature of deposit contracts: the payoff scheme of a standard deposit contract has limited upside gains (cap) but leaves the depositor with the downside risk. Accordingly, depositors do not take into account possible future upside gains of the bank when deciding whether to run the bank or not. Although assumed to be risk neutral, they act as if they were risk averse. ${ }^{4}$ Inefficient bank runs are often related to the phenomenon of depositor coordination failure. ${ }^{5}$ We show that inefficient liquidation might also occur in the absence of a coordination problem.

There exists a vast literature on various aspects of information disclosure. This literature, however, is not bank-specific. ${ }^{6}$ Banks and the banking system as a whole are fundamentally different from other sectors. First, the part of debt finance is much higher at banks than at other firms. The incentives of debtholders differ from those of equityholders. Second, banks are fragile and subject to bank runs and banking crises as they finance long-term investments with short-term debt. And lastly, the banking sector is highly regulated compared to other sectors of the economy. Results from the general information disclosure literature might thus not necessarily be applied to banks. Moreover, there might be some topics that are only (or especially) relevant for the analysis of information disclosure in a banking context.

An increasing number of papers concentrate on transparency issues in the context of banks. There are several theoretical papers that study the effect of transparency on bank stability via market discipline. These papers address the issue of moral hazard in banking, i.e., the banks' incentive for excessive risk taking. Transparency may prevent banks from excessive risk taking and may thus improve their stability by fostering market discipline: providing enough information allows creditors to force the

\footnotetext{
${ }^{4}$ This is the counterpart to the literature on moral hazard in banking where banks do not take into account possible downside risks due to limited liability. Although assumed to be risk neutral, banks behave as if they were risk loving. Their incentive for excessive risk-taking may result in the inefficient continuation of a bank. In our analysis, however, moral hazard is not an issue as banks are exposed to exogenous risk factors only.

${ }^{5}$ There is an extensive literature starting with Diamond and Dybvig (1983) that relates inefficient liquidation to the phenomenon of depositor coordination failure.

${ }^{6}$ For an overview on the theoretical strand of this literature, see Verrecchia (2001); an overview on empirical disclosure literature is provided in Healy and Palepu (2001).
} 
banks to choose the appropriate risk level. The papers thereby concentrate on the depositors' investment decision as a channel for market discipline. The consensus is that transparency indeed reduces risk as it enables depositors to demand adequate compensation - i.e., deposit rates - for given risk-levels. Examples of this literature are Boot and Schmeits (2000), Hyytinen and Takalo (2002, 2004) and Cordella and Yeyati (1998). Some of these papers also account for factors that might dilute the beneficial effect of transparency on bank stability. Hyytinen and Takalo (2002) show how deposit insurance and costs associated with information disclosure reduce, offset or even overcompensate the otherwise beneficial effect of enhanced transparency on the banks' stability.

Recent policy initiatives that call for enhancing transparency in banking - such as Pillar 3 of the new Basel Capital Accord (Basel II) - are also based on the same argument that market discipline can be strengthened - and therefore banks' excessive risk taking reduced - by greater disclosure. Also from a supervisory perspective, there seems to be much consensus that, in the context where banks control their risk, enhancing transparency may be beneficial at best - in that transparency may force banks to behave more prudently — and simply irrelevant ${ }^{7}$ at worst.

As mentioned above, this paper concentrates on the impact of transparency when banks are not able to control their risk exposure. In other words: in contrast to the above mentioned papers, moral hazard is not an issue. In an extension of their model, Cordella and Yeyati (1998) additionally study the impact of disclosure on the ex ante probability of bank failures in the case where the bank's risk level evolves according to exogenous risk factors. In this case, bank transparency reduces bank stability as investors demand higher funding compensation which aggravates the banks' situation. The setup in our paper differs from this exogenous risk version of the Cordella and Yeyati model in the following sense. First, while Cordella and Yeyati compare the polar cases of complete transparency versus complete intransparency, we allow for interior solutions. In doing so, we are able to show how the optimal transparency level varies with the components that determine the exogenous risk. Second, we explicitly model a standard deposit contract. And third, while Cordella and Yeyati focus on the relation between transparency and the funding terms, we concentrate additionally on its

\footnotetext{
${ }^{7}$ Irrelevant in the sense that although all relevant information is disclosed to the market, market discipline does not work. For an example where market discipline may actually lead to an increase in risk, see Blum (2002) .
} 
impact on the depositor's withdrawal decision. In other words, possible consequences of transparency are analyzed in a bank run model.

The impact of transparency might not be the same for individual banks and for the banking sector as a whole. In a bank run model with two banks, Chen and Hasan (2006) show that enhancing transparency of one bank may reduce depositor welfare as it increases the chance of a (inefficient) contagious run on the other bank. Hence, as in our model, enhancing transparency may cause inefficient bank runs. In contrast to our model, however, the result is driven by depositor coordination failure.

In a similar model, Chen and Hasan (2008) illustrate how transparency - the precision of a public signal on bank assets - and depositors' expectation concerning the revelation of the public signal determine whether information-based bank runs improve depositor welfare. If the signal is precise, information-based bank runs are beneficial as they allow the efficient liquidation of a bank. If the signal is noisy, however, bank runs will reduce depositor welfare. In this setup, panic runs - i.e., bank runs where depositors' expectations about the bank fundamentals have not changed - may occur. These runs are triggered by changes in depositors'expectation about the actual revelation of the signal.

The paper is organized as follows. Section 2 describes the setup of the model. The solutions to the depositor's investment and withdrawing decisions and the optimal choice of the bank's transparency level are presented in section 3. Section 4 discusses possible extensions of the model and section 5 concludes.

\section{The Setup}

The optimal transparency decision is analyzed within the framework of a dynamic game of incomplete information. The setup of the model reflects a situation where a bank is hit by a shock, may thus temporarily fall into a stress situation and faces the threat of depositors withdrawing their funds. The outlook of the bank's investment project is, however, favorable. In other words, even in the case where the bank's investment project is hit by a negative shock, its net present value is still positive. The following subsections describe (i) the agents, their action choices, and the timing of the game, (ii) the (exogenously given) distribution of the bank's investment project value and the corresponding payoffs for the agents, and (iii) the information structure and the precise definition of bank transparency. 
Figure 1: Timeline

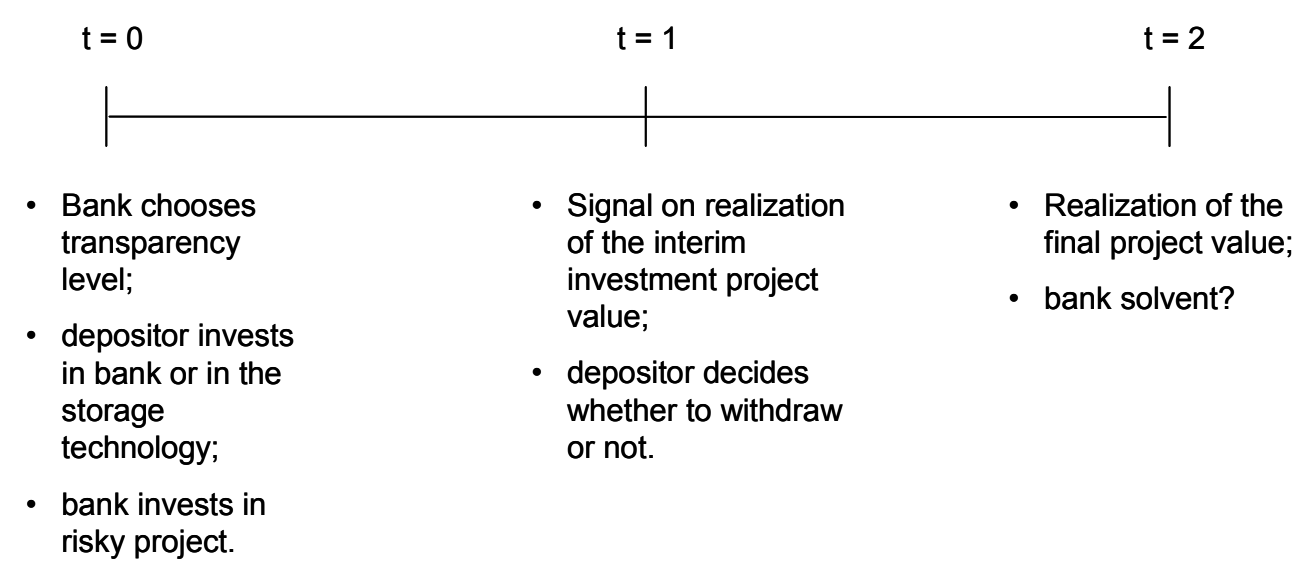

\subsection{Economy, Agents and Timeline}

The economy consists of a bank and a depositor. Both are risk neutral. We assume that the bank is completely financed by a deposit which is normalized to unity. The bank invests the deposit in a risky long-term investment project of which the project value distribution is exogenously given. This project yields a random interim investment project value $\tilde{V}_{1}$ at the interim stage and a random final investment project value $\tilde{V}_{2}$ at the final stage (cf. Section 2.2). At the interim stage, the bank has to disclose information to the market - i.e., to the depositor - on the realization of the interim project value. The bank's action choice is its decision on the transparency level $v$ with respect to the information disclosed. We assume limited liability.

The depositor is thought of as representing a group of large informed investors. Small, uninformed depositors are irrelevant in our context since this group is not expected to exert any form of market discipline. ${ }^{8}$ There is no deposit insurance. The representative depositor with endowment 1 has two action choices. First, he decides whether to invest his endowment in the bank at the gross deposit rate $R^{D} \geq 1$ or to use the storage technology at the safe gross return of 1 . Once invested in the bank, he decides - second - whether to withdraw his deposit or to leave it in the bank. It is assumed that the depositor's withdrawing decision is not contractable.

The depositor decides whether to withdraw or not based on a signal $s^{i}$ on the

\footnotetext{
${ }^{8}$ Note also that only one depositor is needed in our model, as coordination between depositors is not an issue.
} 
realization $i$ of the interim project value he receives. The signal can be interpreted as a financial statement the bank publishes in response to the realization of the shock. The transparency level $v$ initially chosen by the bank defines the precision of this signal (cf. Section 2.3). The transparency level $v$ and the investment project value distribution are common knowledge. The realization of the interim project value, however, is not observable to the depositor.

Figure 1 presents the timeline of the model. There are three periods: $0,1,2$. In $t=0$, the bank chooses its level of transparency $v$, the depositor decides whether to invest its endowment in the bank or to use the storage technology. If he invests in the bank, the bank invests these funds in a risky long-term project.

At the interim stage $t=1$, the depositor receives a signal on the realization of the random interim project value. Based on this signal, he decides whether to withdraw his deposits or not. If he withdraws, the bank is closed early. Otherwise, the bank continues to operate until $t=2$. In $t=2$, the final project value materializes. The bank is closed and it pays back the (gross) deposit rate to the depositor in the case of solvency.

\subsection{Investment Project Value Distribution and Payoffs}

The investment project value distribution is summarized in figure 2. At the interim stage $t=1$, the interim project value $\tilde{V}_{1}$ materializes. The project yields a high interim value $V_{1}^{H} \geq 1$ with probability $q$ and a low value $V_{1}^{L}<1$ with probability $(1-q)$. As the bank's total liabilities amount to 1 , the bank is liquid in the case of $V_{1}^{H}$ but becomes (temporarily) illiquid in the case of $V_{1}^{L}$. For notational and computational simplicity, $V_{1}^{H}$ is set equal to 1 . If the depositor decides to withdraw in $t=1$, he receives either 1 (if $\tilde{V}_{1}=V_{1}^{H} \equiv 1$ ) or $V_{1}^{L}$ (if $\tilde{V}_{1}=V_{1}^{L}$ ); the bank gets nothing. Otherwise, the bank continues to operate until $t=2$.

In $t=2$, the investment project ends and the final project value $\tilde{V}_{2}$ materializes. The distribution of the investment project's final value depends on the state in $t=1$. If, at the interim stage $t=1$, a high interim value has occurred, the project yields a high final project value $V_{2}^{H}>1$ with probability 1 . If a low interim value has materialized, however, $V_{2}^{H}$ will only be achieved with probability $p$. With probability $(1-p)$, the investment project yields a low value $V_{2}^{L}<V_{1}^{L}$. For notational and computational 


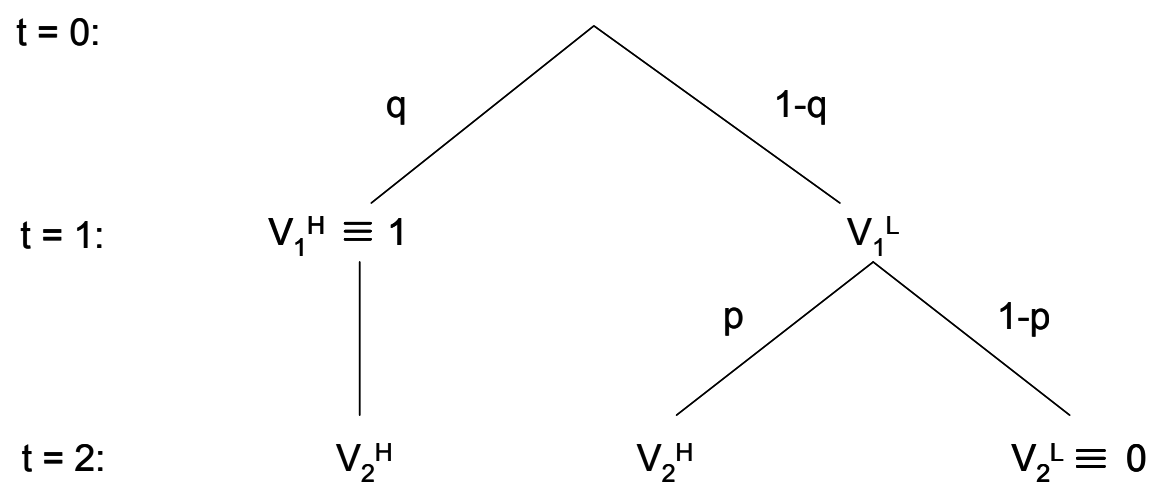

simplicity, $V_{2}^{L}$ is set equal to zero. ${ }^{9}$ It is assumed that $p \leq q$. In other words: the probability of success from the first technology is equal to or higher than the probability of success from the second technology. The bank remains solvent if $V_{2}^{H}$ is realized and is insolvent otherwise. In other words:

$$
V_{2}^{H} \geq R^{D}>1>V_{1}^{L}>0
$$

We assume that the expected investment project value is higher than or equal to the value from the alternative option, the storage technology:

$$
q V_{2}^{H}+(1-q) p V_{2}^{H} \geq 1
$$

Inequality (2) is a necessary condition for the existence of the bank: if the sure payoff from using the storage technology is higher than the expected payoff from investing in the risky project, a bank would not exist. We further assume that - given a low project value in $t=1$ - the expected final investment project value from continuing the investment project is higher than the value from stopping the project and closing the bank in $t=1$ :

$$
p V_{2}^{H} \geq V_{1}^{L}
$$

Inequality (3) implies that the case of efficient liquidation of a bank is ruled out in this model by assumption. ${ }^{10}$

\footnotetext{
${ }^{9}$ The results do not change qualitatively due to the simplifications with respect to $V_{1}^{H}$ und $V_{2}^{L}$.

${ }^{10}$ For a model where bank runs are efficient, see, e.g., Allen and Gale (1998). Chen and Hasan (2006) analyze the relation between transparency of banks and the efficiency of bank runs.
} 
Lastly, we assume that - given a low project value in $t=1$ - the depositor's payoff from withdrawing in the bad state is equal or greater than the expected payoff from not withdrawing in the bad state:

$$
V_{1}^{L} \geq p R^{D}
$$

Inequality (4) is assumed to restrict the attention to only those cases where there is a conflict of interest between the bank and the depositor. If inequality (4) did not hold, the depositor would have no incentive at all to withdraw its deposits.

In the solvency case, the depositor receives his promised deposit rate $R^{D}$, while the bank gets the difference between the final investment project value $V_{2}^{H}$ and the deposit rate $R^{D}$. If the bank becomes insolvent in $t=2$, however, neither the bank nor the depositor receives anything. The distribution of the bank's and the depositor's payoffs - conditional on the realization of the bank's investment project values and the depositor's withdrawal decision — are summarized in Table 1 and Table 2.

Table 1: Payoff structure if bank is closed in period 1

\begin{tabular}{l||c|c}
\hline \multicolumn{1}{c||}{} & \multicolumn{2}{c}{ Realization of $\vec{V}_{1}:$} \\
\hline & $V_{1}^{H} \equiv 1$ & $V_{1}^{L}$ \\
\hline \hline Bank: & 0 & 0 \\
\hline Depositor: & 1 & $V_{1}^{L}$ \\
\hline \hline
\end{tabular}

Table 2: Payoff structure if bank operates until period 2

\begin{tabular}{l||c|c}
\hline \multicolumn{1}{c||}{} & \multicolumn{2}{c}{ Realization of $V_{2}:$} \\
\hline \hline Bank: & $V_{2}^{H}$ & $V_{2}^{L} \equiv 0$ \\
\hline Depositor: & $V_{2}^{H}-R^{D}$ & 0 \\
\hline \hline
\end{tabular}

\subsection{Information Structure and Transparency}

While the investment project value distribution is common knowledge, the realization of the interim project value is not observable by the depositor. However, in $t=1$, the bank has to disclose information on the state of the bank to the market. At the interim stage, thus, the depositor receives a signal $s^{i}$ on the realization $i$ of the interim project value $\tilde{V}_{1}$, where $s^{H}$ is pointing to a high interim project value $V_{1}^{H}$ and $s^{L}$ to 
a low interim project value $V_{1}^{L}$. Given that the distribution of the final project value $\tilde{V}_{2}$ is related to the realization of the interim project value $\tilde{V}_{1}$, the signal serves as an indicator of the probability that the bank remains solvent in $t=2$.

The level of transparency initially chosen by the bank is defined as the precision of the signal. Concretely, transparency is defined as the conditional probability of signal $s^{i}$ given the realization $i$ of the random interim project value $\tilde{V}_{1}$ :

$$
\begin{aligned}
v & =\operatorname{prob}\left[s^{i} \mid V_{1}^{i}\right], \quad i=L, H \\
(1-v) & =\operatorname{prob}\left[s^{i} \mid V_{1}^{j}\right], \quad i=L, H ; \quad j=L, H ; \quad i \neq j
\end{aligned}
$$

with $v \in[0.5,1]$. The more transparent the bank, the more precise is the signal on the actual state of the investment project in $t=1$. Or, in other words: the higher the transparency level, the higher the probability that the depositor receives the correct signal. ${ }^{11}$ If the transparency level $v$ is set to 0.5 , the signal does not contain any new information compared to the information available in $t=0$. This corresponds to the case of complete intransparency. If $v=1$, then the signal reflects the realization of the interim project value perfectly, i.e., there is complete transparency.

Enhancing transparency, however, is costly for the bank. We assume a convex cost function $c(v)$ with the following properties:

$$
\begin{aligned}
& c(0.5)=0, \\
& c^{\prime}(v) \geq 0, \quad c^{\prime \prime}(v)>0, \quad c^{\prime}(0.5)=0, \quad c^{\prime}(1)=\infty
\end{aligned}
$$

Costs may arise because the bank has to produce comprehensive information on its financial performance - the state of the investment project in $t=1$ - and to disclose it to the depositor. Moreover, costs may also arise because the bank and/or the investment have to be (re-)organized such as to become transparent. It is assumed that the higher the transparency level, the more costly it gets to enhance transparency further. Figure 3 summarizes the game described in Section 2.

\footnotetext{
${ }^{11}$ As the recent crisis has shown, there exists various ways to make it hard for investors to get a clear picture of the actual situation of a bank. Examples are disclosing only partial information or "hiding" the relevant pieces of information within a bulk of irrelevant figures.
} 


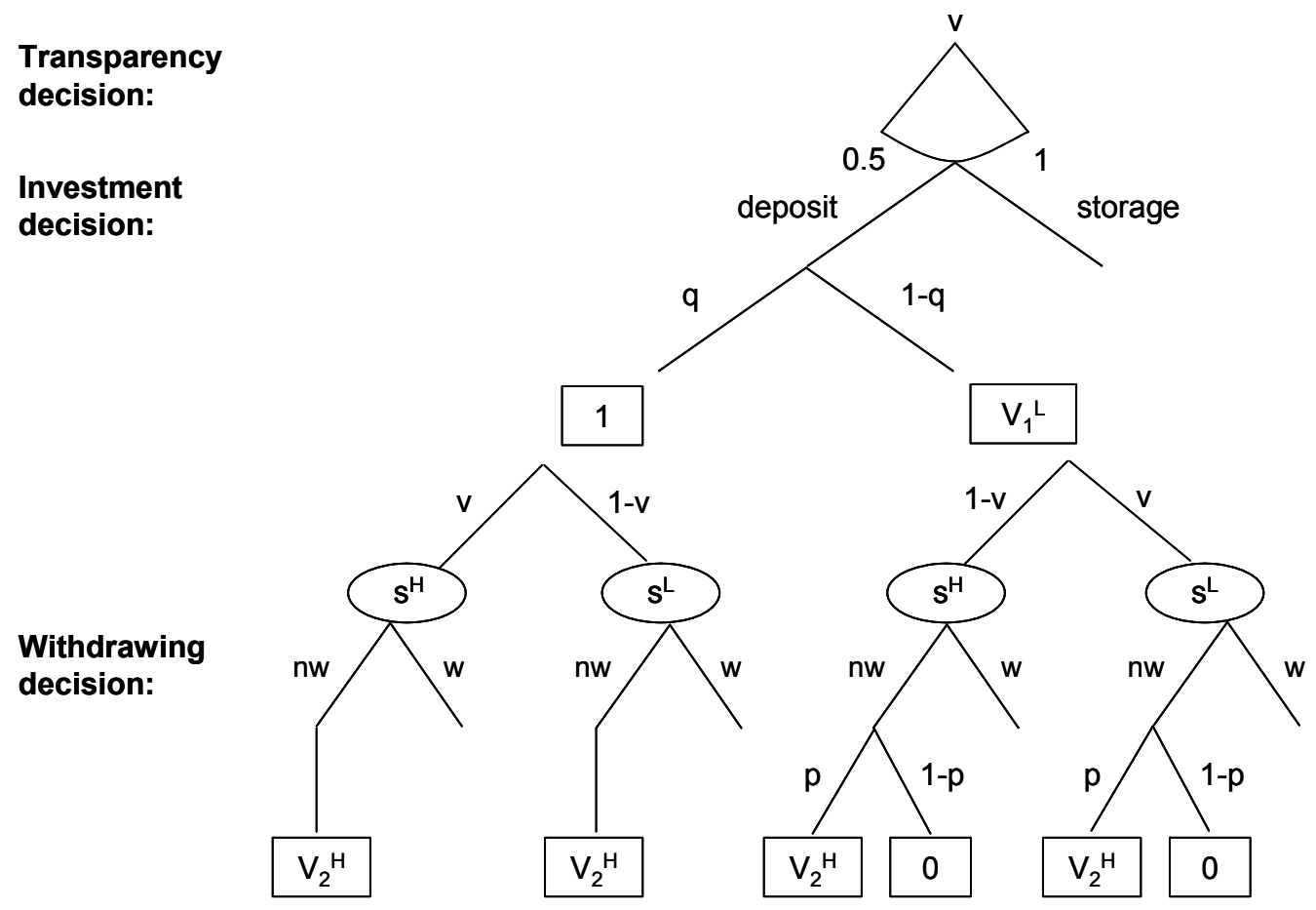

\section{The Game and Its Equilibria}

As a reference point to the Perfect Bayesian Equilibrium to be derived for the game according to figure 3, the first-best allocation of the model is presented first. A firstbest allocation is characterized by the lack of inefficiencies arising, e.g., from incentive problems or imperfect information. Hence, the representation of the model in the firstbest world reduces to the project value distribution given in figure 2. The corresponding first-best allocation is presented in proposition 1.

Proposition 1 The first-best allocation is characterized by (i) the investment in the project takes place in $t=0$ and (ii) the project is not liquidated in $t=1$.

Not investing in the project as well as early liquidation of the project is inefficient.

Proof. By assumptions (2) and (3), the expected investment project value is alwaysi.e., at any stage in the game - higher or equal than the payoff from the alternative option.

The following sections derive the solution to the game as described by figure 3 taking into account imperfect information and the agents' incentive compatible behavior. 
The game has to be solved by backward induction. We start with the depositor's withdrawing decision in $t=1$. Based on this result, we turn to the depositor's investment decision in $t=0$. Finally, we analyze the optimal bank transparency decision.

\subsection{The Depositor's Withdrawing Decision}

After being hit by a shock in $t=1$, the bank has to disclose information on its actual situation. Based on this information - i.e., the signal $s^{i}$ on the realization $i$ of the interim project value $\tilde{V}_{1}$ - the depositor has to decide whether to withdraw his funds or to leave them in the bank. According to the two possible outcomes of the signal, we distinguish between two cases. ${ }^{12}$

Case 1: If a low signal is observed in $t=1$, the depositor withdraws if the expected payoff from withdrawing

$$
\begin{aligned}
E\left[P^{D}(w) \mid s^{L}\right] & =\operatorname{prob}\left[V_{1}^{L} \mid s^{L}\right] \cdot V_{1}^{L}+\operatorname{prob}\left[V_{1}^{H} \mid s^{L}\right] \cdot 1 \\
& =\frac{(1-q) v}{(1-q) v+q(1-v)} V_{1}^{L}+\frac{q(1-v)}{(1-q) v+q(1-v)}
\end{aligned}
$$

is greater than or equal to the expected payoff from not withdrawing

$$
\begin{aligned}
E\left[P^{D}(n w) \mid s^{L}\right] & =\operatorname{prob}\left[V_{1}^{L} \mid s^{L}\right] \cdot p R^{D}+\operatorname{prob}\left[V_{1}^{H} \mid s^{L}\right] \cdot R^{D} \\
& =\frac{(1-q) v}{(1-q) v+q(1-v)} p R^{D}+\frac{q(1-v)}{(1-q) v+q(1-v)} \cdot R^{D}
\end{aligned}
$$

Thus, the depositor withdraws in the case of a low signal if

$$
\frac{(1-q)\left(V_{1}^{L}-p R^{D}\right)}{q\left(R^{D}-1\right)} \geq \frac{1-v}{v}
$$

Case 2: If a high signal is observed in $t=1$, the depositor does not withdraw if the expected payoff from not withdrawing

$$
\begin{aligned}
E\left[P^{D}(n w) \mid s^{H}\right] & =\operatorname{prob}\left[V_{1}^{H} \mid s^{H}\right] \cdot R^{D}+\operatorname{prob}\left[V_{1}^{L} \mid s^{H}\right] \cdot p R^{D} \\
& =\frac{q v}{q v+(1-q)(1-v)} R^{D}+\frac{(1-q)(1-v)}{q v+(1-q)(1-v)} p R^{D}
\end{aligned}
$$

\footnotetext{
${ }^{12}$ The derivation of the conditional probabilities of the good and the bad state given a high or a low signal is presented in section 3.2 .
} 
is greater than or equal to the expected payoff from withdrawing

$$
\begin{aligned}
E\left[P^{D}(w) \mid s^{H}\right] & =\operatorname{prob}\left[V_{1}^{H} \mid s^{H}\right] \cdot 1+\operatorname{prob}\left[V_{1}^{L} \mid s^{H}\right] \cdot V_{1}^{L} \\
& =\frac{q v}{q v+(1-q)(1-v)}+\frac{(1-q)(1-v)}{q v+(1-q)(1-v)} V_{1}^{L}
\end{aligned}
$$

Thus, the depositor does not withdraw in the case of a high signal if

$$
\frac{(1-q)\left(V_{1}^{L}-p R^{D}\right)}{q\left(R^{D}-1\right)} \leq \frac{v}{1-v}
$$

In what follows, we assume that inequalities (9) and (12) hold, i.e., we assume

$$
\frac{(1-v)}{v} \leq \frac{(1-q)\left(V_{1}^{L}-p R^{D}\right)}{q\left(R^{D}-1\right)} \leq \frac{v}{(1-v)} \quad \forall v \in(0.5,1]
$$

Under assumption (13), the depositor withdraws after receiving a low signal and does not withdraw after receiving a high signal. This allows us to concentrate on those cases where the information disclosed to the depositor - and therefore also the bank's transparency choice - has an influence on the depositor's decision to withdraw. In other words: assumption (13) describes the conditions under which the signal transmits valuable information. If this assumption did not hold, the a priori information on expected payoffs would completely dominate and the signal would be worthless. Inequality (13), however, is only assumed to hold for $v>0.5$. In the case of complete intransparency, i.e., for $v=0.5$, the signal does not contain any new information compared to the information available in $t=0$. Hence, the depositor will not withdraw provided that investing in $t=0$ has been preferred to using the storage technology (cf. Section 3.2).

The inequalities in assumption (13) relate transparency to the depositor's payoff distribution. The fraction in the middle relates (i) the depositor's expected excess payoff from withdrawing over not withdrawing in the bad state weighted by the (prior) probability of being in the bad state (nominator) to (ii) the depositor's expected excess payoff from not withdrawing over withdrawing in the good state weighted by the (prior) probability of being in the good state (denominator). Comparing these two weighted expected excess payoffs can be interpreted as assessing the opportunity costs arising from choosing the wrong action. The higher the precision of the signal, i.e., the higher the transparency level $v$, the more these expected excess payoffs are allowed to differ 
while still fulfilling condition (13): If - for example - the depositor receives a low signal $s^{L}$ and is almost sure that a low interim project value $V_{1}^{L}$ has materialized-i.e., $v$ is almost 1 - he will withdraw even if the prior information on the excess payoffs are in favour of not withdrawing. Concretely, he will withdraw even if $q\left(R^{D}-1\right)$ - the weighted expected excess payoff from not withdrawing over withdrawing in the good state - is much higher than $(1-q)\left(V_{1}^{L}-p R^{D}\right)$ - the weighted expected excess payoff from withdrawing over not withdrawing in the bad state.

Under condition (13), the depositor always withdraws when he observes a signal indicating that the fundamentals of the bank are weak. Compared to the efficient allocation as outlined in proposition 1 , however, this solution is inefficient. The efficient solution would only be achieved if either not withdrawing was the dominant strategy ${ }^{13}$ or the optimal bank transparency choice would always be complete intransparency (i.e., $v^{*}=0.5$ ), independent of the bank's risk profile. However, not withdrawing as a dominant strategy is ruled out by assumption (13) and complete intransparency might but does not necessarily have to be optimal (see section 3.3).

\subsection{The Depositor's Investment Decision}

Based on the transparency level chosen and the interest rate offered by the bank in $t=0$, the depositor decides whether to invest his endowment of 1 in the bank or to use the storage technology. The depositor invests in the bank if his expected payoff from investing in the bank, $E\left[P^{D}\right]$, is greater than or equal to the payoff from storing, where

$$
E\left[P^{D}\right]=E\left[P^{D} \mid s^{H}\right] \cdot \operatorname{prob}\left(s^{H}\right)+E\left[P^{D} \mid s^{L}\right] \cdot \operatorname{prob}\left(s^{L}\right)
$$

The depositor's expected payoff from investing, $E\left[P^{D}\right]$, is the sum of (i) his expected payoff given that a high signal is observed, $E\left[P^{D} \mid s^{H}\right]$, weighted by the probability of observing a high signal, $\operatorname{prob}\left(s^{H}\right)$, and (ii) his expected payoff given that a low signal is observed, $E\left[P^{D} \mid s^{L}\right]$, weighted by the probability of observing a low signal, $\operatorname{prob}\left(s^{L}\right)$. The probability of observing signal $s^{i}$ is given by

$$
\operatorname{prob}\left(s^{i}\right)=\operatorname{prob}\left(s^{i} \mid V_{1}^{i}\right) \cdot \operatorname{prob}\left(V_{1}^{i}\right)+\operatorname{prob}\left(s^{i} \mid V_{1}^{j}\right) \cdot \operatorname{prob}\left(V_{1}^{j}\right)
$$

\footnotetext{
${ }^{13}$ I.e., if the depositor's payoff distribution was such that even when receiving a bad signal, the depositor decides not to withdraw.
} 
Thus:

$$
\begin{aligned}
& \operatorname{prob}\left(s^{H}\right)=q v+(1-q)(1-v) \\
& \operatorname{prob}\left(s^{L}\right)=(1-q) v+q(1-v)
\end{aligned}
$$

We next turn to the depositor's expected payoffs conditional on the signal observed. Under assumption (13), the depositor withdraws after observing a low signal and does not withdraw after observing a high signal. The depositor's expected payoff conditional on observing $s^{L}\left(s^{H}\right)-E\left[P^{D} \mid s^{L}\right]\left(E\left[P^{D} \mid s^{H}\right]\right)$-is thus the sum of (i) the payoff from withdrawing (not withdrawing) in the bad (good) state weighted by the conditional probability of being in the bad (good) state and (ii) the payoff from withdrawing (not withdrawing) in the good (bad) state weighted by the conditional probability of being in the good (bad) state:

$$
\begin{aligned}
E\left[P^{D} \mid s^{L}\right] & =\operatorname{prob}\left(V_{1}^{L} \mid s^{L}\right) \cdot V_{1}^{L}+\operatorname{prob}\left(1 \mid s^{L}\right) \cdot 1 \\
E\left[P^{D} \mid s^{H}\right] & =\operatorname{prob}\left(1 \mid s^{H}\right) \cdot R^{D}+\operatorname{prob}\left(V_{1}^{L} \mid s^{H}\right) \cdot p R^{D}
\end{aligned}
$$

The conditional probabilities of the bad and good state, respectively, are given by

$$
\begin{gathered}
\operatorname{prob}\left(V_{1}^{L} \quad \mid s^{L}\right)=\frac{\operatorname{prob}\left(V_{1}^{L} \cup s^{L}\right)}{\operatorname{prob}\left(s^{L}\right)}=\frac{(1-q) v}{(1-q) v+q(1-v)} \\
\operatorname{prob}\left(V_{1}^{L} \quad \mid s^{H}\right)=\frac{\operatorname{prob}\left(V_{1}^{L} \cup s^{H}\right)}{\operatorname{prob}\left(s^{H}\right)}=\frac{(1-q)(1-v)}{q v+(1-q)(1-v)} \\
\operatorname{prob}\left(1 \quad \mid s^{L}\right)=\frac{\operatorname{prob}\left(1 \cup s^{L}\right)}{\operatorname{prob}\left(s^{L}\right)}=\frac{q(1-v)}{(1-q) v+q(1-v)} \\
\operatorname{prob}\left(1 \quad \mid s^{H}\right)=\frac{\operatorname{prob}\left(1 \cup s^{H}\right)}{\operatorname{prob}\left(s^{H}\right)}=\frac{q v}{q v+(1-q)(1-v)}
\end{gathered}
$$

Taking equations (15) to (23) together yields

$$
E\left[P^{D}\right]=q v R^{D}+(1-q)(1-v) p R^{D}+(1-q) v V_{1}^{L}+q(1-v)
$$

The depositor invests in the bank if the expected payoff from investing is greater than or equal to the (sure) payoff from the storage technology, i.e., if

$$
q v R^{D}+(1-q)(1-v) p R^{D}+(1-q) v V_{1}^{L}+q(1-v) \geq 1
$$


or

$$
R^{D} \geq \frac{1-(1-q) v V_{1}^{L}-q(1-v)}{q v+(1-q) p(1-v)} \equiv R_{c r i t}^{D}(v)
$$

$R_{c r i t}^{D}(v)$ (henceforth $R_{c r i t}^{D}$ ) is the critical value for the deposit rate. It represents the lower threshold for the deposit rate to which the depositor is indifferent between investing in the bank and using the storage technology. In other words, inequality (26) represents the depositor's participation constraint. The level of $R_{\text {crit }}^{D}$ is a function of the parameters describing the investment project value distribution-i.e., the bank's risk profile - and the transparency level chosen by the bank. As will be shown in section 3.4 , this level is strictly decreasing with the project value distribution parameters. Moreover, the critical deposit rate is also negatively related to the transparency level $v$. The less transparent the bank, the more the bank has to pay to the depositor to attract funding. Hence, while increasing transparency is costly as assumed in equation (6), it also reduces a component in the bank's overall cost function, namely the funding costs.

Proposition 2 The critical value for the deposit rate, $R_{c r i t}^{D}$, is strictly decreasing with the transparency level $v$.

Proof. Differentiating the critical value for the deposit rate, $R_{c r i t}^{D}$, with respect to the transparency level $v$ yields:

$$
\frac{\partial R_{c r i t}^{D}}{\partial v}=\frac{(1-q)\left[p-q-(1-q) p V_{1}^{L}\right]}{[q v+(1-q) p(1-v)]^{2}}<0
$$

which is negative given that $V_{1}^{L}<1$ and $p \leq q$ by assumption. ${ }^{14}$

\subsection{The Optimal Decision on the Transparency Level}

We next turn to the bank's decision on the optimal transparency level $v$. The higher the transparency level $v$, the higher the precision of the signal $s^{i}$ on the realization $i$ of the interim investment project value $\tilde{V}_{1}$. The bank chooses the level of transparency

\footnotetext{
${ }^{14}$ The assumption $p \leq q$ is a sufficient but not a necessary condition to ensure that the critical value of the deposit rate $R_{c r i t}^{D}$ is decreasing with the transparency level $v$.
} 
that maximizes its expected payoff, $E\left[P^{B}(v)\right]$, subject to the depositor's participation constraint (inequality 26$)^{15}$ :

$$
\begin{aligned}
\max E\left[P^{B}(v)\right]= & q v\left(V_{2}^{H}-R^{D}\right) \\
& +(1-q)(1-v) p\left(V_{2}^{H}-R^{D}\right) \\
& -c(v) \\
\text { s.t. } R^{D} \geq & \frac{1-(1-q) v V_{1}^{L}-q(1-v)}{q v+(1-q) p(1-v)}
\end{aligned}
$$

The first line in equation (28) describes the bank's expected payoff in the good state while the second line represents the bank's expected payoff in the bad state. The third line corresponds to the (direct) costs associated with the level of transparency as characterized in equation (6).

Since the depositor's participation constraint holds as an equality, it can be inserted into the bank's expected payoff function. Hence, the bank's maximization problem can be restated as:

$$
\begin{aligned}
\max E\left[P^{B}(v)\right]= & q v V_{2}^{H}+(1-q)(1-v) p V_{2}^{H} \\
& +(1-q) v V_{1}^{L}+q(1-v)-1 \\
& -c(v)
\end{aligned}
$$

The corresponding first-order condition (FOC) is given by:

$$
\frac{\partial E\left[P^{B}(v)\right]}{\partial v}=q\left(V_{2}^{H}-1\right)-(1-q)\left(p V_{2}^{H}-V_{1}^{L}\right)-c^{\prime}(v)
$$

The FOC relates the expected marginal project value of an additional unit of transparency - the first term in equation (31) - to the expected marginal costs - the last two terms in equation (31). The expected marginal costs of an additional unit of transparency consist of two components: The direct marginal costs - represented by the last term in equation (31) and stemming from the transparency cost function as characterized in equation (6) — and the indirect marginal costs.

\footnotetext{
${ }^{15}$ Note that although the setup of the maximization problem corresponds to the one of a monopoly bank, the result with respect to the optimal transparency level does not change if the banking sector was assumed to be competitive. As will be shown below, the solution to the bank's maximization problem is identical to the socially optimal level of transparency. In other words: the market structure in this setup is irrelevant with respect to the solution for the optimal transparency level. It would only affect the distribution of the surplus.
} 
Proposition 3 If the expected marginal project value of an additional unit of transparency is equal to or lower than the expected indirect marginal costs, i.e., if

$$
q\left(V_{2}^{H}-1\right) \leq(1-q)\left(p V_{2}^{H}-V_{1}^{L}\right)
$$

then the optimal level of transparency is $v^{*}=0.5$, i.e., complete intransparency.

If, however, the expected marginal project value of an additional unit of transparency is greater than the expected indirect marginal costs - i.e., inequality (32) does not hold - an interior solution exists for the optimal transparency level $v^{*}$.

Proof. If inequality (32) holds, the FOC in equation (31) is negative. Hence, the optimal transparency level is the lowest possible one which corresponds to $v^{*}=0.5$, the case of complete intransparency.

If, however, inequality (32) does not hold, the FOC becomes positive under complete intransparency $(v=0.5)$ :

$$
\frac{\partial E\left[P^{B}(v)\right]}{\partial v}(0.5)=q\left(V_{2}^{H}-1\right)-(1-q)\left(p V_{2}^{H}-V_{1}^{L}\right)>0
$$

It is thus no longer optimal to choose complete intransparency, but a certain positive level of transparency. Complete transparency is, however, also not optimal as the bank's expected payoff function is concave:

$$
\frac{\partial^{2} E\left[P^{B}(v)\right]}{\partial v^{2}}=-c^{\prime \prime}(v)<0
$$

Hence: If inequality (32) does not hold, there exists an interior solution for the transparency level $v$. The exact solution $v^{*}$ depends on the values for the parameters describing the investment project value distribution.

Ignoring the direct costs for the moment, inequality (32) represents the trade-off the bank faces with respect to the transparency level. Roughly speaking, both sides of inequality (32) can be interpreted as opportunity costs of liquidating, either in the good (left hand side) or in the bad (right hand side) state. The trade-off with respect to transparency is best illustrated by the project value distribution tree (figure 2). The left hand side of inequality (32), the expected marginal project value, corresponds to the left branch of this tree. Precisely, it corresponds to the difference between the 
project value from continuing and the project value from liquidating in the good state, weighted by the probability of being in the good state. In the case of the good state, the bank prefers transparency to intransparency. In other words, the bank wants the signal to reflect the correct state of the bank to prevent the depositor from withdrawing.

If the bad state has materialized, however, intransparency is preferred to transparency to prevent an inefficient bank run. This preference is reflected in the right hand side of inequality (32) which corresponds to the right branch of the project value distribution tree (figure 2). It is the difference between the project value from continuing and the project value from liquidating in the bad state, weighted by the probability of being in the bad state.

The higher the expected project value difference in the bad compared to the one in the good state, the higher the opportunity costs of liquidating in the bad compared to the ones in the good state, and therefore the lower the transparency level chosen by the bank. In the case where the expected project value difference in the bad state (right hand side of inequality (32)), is higher than the one in the good state (left hand side of inequality (32)), the bank chooses complete intransparency, i.e., $v^{*}=0.5$. In the opposite case, the bank chooses a positive level of transparency of which the exact level depends on the direct costs as well as on the bank's risk profile parameters.

Inequality (32) is more likely to be satisfied (i) the lower the probability $q$ of a high interim project value, (ii) the higher the probability $p$ of achieving the high final project value despite a low interim value and (iii) the lower the value of the low interim project value $V_{1}^{L}$. The lower $q$ and $V_{1}^{L}$ are and the higher $p$ is, the more dominant the indirect marginal costs become compared to the marginal expected project value of an additional unit of transparency, i.e., the more dominant the right hand side of the project value distribution tree (figure 2) becomes.

So far, we have derived the optimal solution for the transparency level from the bank's point of view. However, calls for enhancing transparency in the banking sector are based on the assumption that banks are reluctant to disclose information to investors and depositors and that bank transparency might therefore be too low compared to its socially optimal level. Would social welfare be enhanced in this setup by increasing the transparency level above the bank's optimal solution?

Proposition 4 In this setup, deviating from the bank's solution for the transparency level is not socially optimal. Enhancing transparency above the level chosen by the bank 
decreases social welfare.

Proof. The socially optimal transparency level $v_{S W}^{*}$ is the level that maximizes expected social welfare:

$$
\begin{aligned}
\max E[S W(v)]= & q v V_{2}^{H}+q(1-v) \\
& +(1-q)(1-v) p V_{2}^{H}+(1-q) v V_{1}^{L} \\
& -c(v)
\end{aligned}
$$

As the corresponding FOC

$$
\frac{\partial E[S W(v)]}{\partial v}=q\left(V_{2}^{H}-1\right)-(1-q)\left(p V_{2}^{H}-V_{1}^{L}\right)-c^{\prime}(v)
$$

coincides with the FOC from the bank's maximization problem (equation (31)), the socially optimal transparency level $v_{S W}^{*}$ equals the bank's optimal transparency level $v^{*}$. Hence: deviating from the bank's solution for the transparency level decreases social welfare in this setup.

According to proposition 4, enhancing transparency above the bank's solution for the transparency level is not socially optimal in this setup. ${ }^{16}$

To summarize, enhancing transparency has the following three effects: On the positive side, enhancing the transparency level $v$ decreases the probability of an (inefficient) bank run in the case of a high signal (reflected by the first term in equation (31)). On the negative side, however, an increase in the transparency level increases (i) the probability of an (inefficient) bank run in the case of a low signal (reflected by the second term in equation (31)) as well as (ii) the direct costs of transparency (reflected by the last term in equation (31)).

\subsection{Comparative Statics Analysis}

In what follows, we assume that inequality (32) does not hold. In other words, we assume that the expected marginal project value of an additional unit of transparency exceeds the latter's expected indirect marginal costs. The aim here is to analyze how the optimal solution for the transparency level $v^{*}$ and the critical value for the deposit

\footnotetext{
${ }^{16}$ Note that in this setup, many issues inherently linked to banking and transparency are ignored. Section 4 provides a discussion of some of these issues.
} 
rate $R_{c r i t}^{D}$ vary with the parameters describing the bank's risk profile. ${ }^{17}$ In fact, both variables are a function of these parameters. Both values vary with the probability $q$ of a high interim project value and the probability $p$ of a high final project value given a low interim value. ${ }^{18}$

Proposition 5 If inequality (32) does not hold, the optimal transparency level $v^{*}$ is strictly increasing in the probability $q$ of a high interim project value and strictly decreasing in the probability $p$ of a high final project value given a low interim value has materialized in $t=1$.

Proof. Define a function $F\left(v^{*}, q\right)$ and a function $G\left(v^{*}, p\right)$ such that

$$
F\left(v^{*}, q\right) \equiv \frac{\partial E\left[\tilde{V}_{2}(v)\right]}{\partial v}=0
$$

and

$$
G\left(v^{*}, p\right) \equiv \frac{\partial E\left[\tilde{V}_{2}(v)\right]}{\partial v}=0
$$

Taking the total differential of $F\left(v^{*}, q\right)$ and $G\left(v^{*}, p\right)$ yields:

$$
\begin{aligned}
& \frac{\partial F}{\partial v} d v^{*}+\frac{\partial F}{\partial q} d q=0 \\
& \frac{\partial G}{\partial v} d v^{*}+\frac{\partial G}{\partial p} d p=0
\end{aligned}
$$

or

$$
\begin{gathered}
\frac{d v^{*}}{d q}=-\frac{\frac{\partial F}{\partial q}}{\frac{\partial F}{\partial v}} \\
\frac{d v^{*}}{d p}=-\frac{\frac{\partial G}{\partial p}}{\frac{\partial G}{\partial v}}
\end{gathered}
$$

According to equations (40) and (41), we obtain the influence of a unit change in $q$ and $p$ on the optimal transparency level $v^{*}$ by calculating the partial derivatives of

\footnotetext{
${ }^{17}$ If inequality (32) does not hold, the optimal transparency level is complete intransparency, regardless of the bank's risk parameters.

${ }^{18}$ In addition to the risk distribution parameters, the critical value for the deposit rate $R_{c r i t}^{D}$ is also a function of the transparency level $v$ (see proposition 2).
} 
the functions $F\left(v^{*}, q\right)$ and $G\left(v^{*}, p\right)$. We have

$$
\begin{gathered}
\frac{\partial F}{\partial v}=-c^{\prime \prime}(v)<0 \\
\frac{\partial F}{\partial q}=V_{2}^{H}-1+p V_{2}^{H}-V_{1}^{L}>0
\end{gathered}
$$

where $\frac{\partial F}{\partial q}>0$ given that $V_{1}^{L} \leq p V_{2}^{H}$ by assumption (3), and

$$
\begin{gathered}
\frac{\partial G}{\partial v}=-c^{\prime \prime}(v)<0 \\
\frac{\partial G}{\partial p}=-(1-q) V_{2}^{H}<0
\end{gathered}
$$

Hence: an increase in the probability $q$ of a high interim project value is associated with an increase in the optimal transparency level $v^{*}$, i.e., $\frac{d v^{*}}{d q}>0$. An increase in the probability $p$ of a high final project value given a low interim value has materialized in $t=1-$ is, however, associated with a decrease in the optimal transparency level $v^{*}$, i.e., $\frac{d v^{*}}{d p}<0$.

Proposition 5 states that-for a sufficiently small level of the low interim project value $V_{1}^{L}$ as is assumed in inequality (3) - the higher the probability $q$ of a high investment project value in $t=1$, the higher the optimal transparency level $v^{*}$ chosen by the bank. The more likely it is that the bank will be in the good state in $t=1$, the more willing the bank shows in $t=0$ to disclose the actual state in $t=1$ in order to avoid a run. The condition on the low interim project value $V_{1}^{L}$ (inequality (3)) is a sufficient but not a necessary condition to assure that in $t=1$, the expected payoff from continuing is higher than the payoff from liquidating. ${ }^{19}$ If the low interim project value is too high, then the probability $q$ of a high interim project value does not play a role anymore.

\footnotetext{
${ }^{19}$ The necessary condition to assure that $\frac{\partial F}{\partial q}>0$ is:

$$
1+V_{1}^{L}<V_{2}^{H}+p V_{2}^{H}
$$

The left-hand side of the above inequality is the expected payoff from liquidating while the righthand side corresponds to the expected payoff from continuing.
} 
Proposition 5 also states that the higher the probability $p$ of a high final project value given a low interim value in $t=1$ - the lower the optimal transparency level $v^{*}$ the bank chooses. The higher this probability $p$, the higher the expected payoff from continuing becomes compared to the payoff from liquidating in $t=1$. Given that a low interim return has materialized in $t=1$, however, continuing becomes more likely the lower the level of transparency.

Proposition 6 The critical value for the deposit rate, $R_{c r i t}^{D}$, is strictly decreasing with (i) the probability $q$ of a high interim project value, and (ii) the probability $p$ of a high final project value $V_{2}^{H}$ given a low interim value in $t=1$.

Proof. Differentiating the critical value for the deposit rate, $R_{c r i t}^{D}$, with respect to (i) the probability $q$ of a high interim project value, and (ii) the probability $p$ of a high final project value $V_{2}^{H}$ given a low interim value in $t=1$ yields:

$$
\begin{aligned}
\frac{\partial R_{\text {crit }}^{D}}{\partial q} & =\frac{v\left[v V_{1}^{L}+p(1-v)-1\right]}{[q v+(1-q) p(1-v)]^{2}}<0 \\
\frac{\partial R_{c r i t}^{D}}{\partial p} & =\frac{(1-q)(1-v)\left[(1-q) v V_{1}^{L}+q(1-v)-1\right]}{[q v+(1-q) p(1-v)]^{2}}<0
\end{aligned}
$$

which are both negative given that $v \in[0.5,1]$ and $p \in[0,1]$ by definition and $V_{1}^{L}<1$ by assumption.

Proposition 6 states that the critical value for the deposit rate is negatively related to the probabilities of a high interim project value, $q$, and a high final project value $p$ given a low interim value. The higher these probabilities, the higher the probability that the bank will remain solvent and the depositor will actually receive the promised repayment in $t=2$, and therefore the lower the repayment the bank has to promise to get the depositor investing in the bank.

\section{Discussion}

This section addresses robustness issues and possible extensions of the model presented in the previous sections.

First, the result in our model is driven by the characteristics of the deposit contract. The payoff scheme of the deposit contract prevents the implementation of the first-best 
solution. To minimize the probability of a bank run, the optimal solution in our model is to allow for some degree of intransparency. However, inefficient bank runs could also be ruled out by allowing for renegotiation. The bank could - in principle - renegotiate the deposit contract in the case of a bad state at the interim stage by offering a higher deposit rate. In other words, the bank could compensate the depositor for the risk from leaving the deposit in the bank until the end of the game, despite the bank's bad state in the interim period. If this were possible, no run would occur in our model. However, renegotiation is not observed in practice and we therefore think that a standard deposit contract promising a fixed return and no possibility for renegotiation is a reasonable assumption.

Similarly, the bank could also offer a state-contingent deposit contract to avoid a bank run. In other words, the bank could offer a deposit rate contingent on the state of the bank at the interim period and the corresponding signal observed, respectively. However, while there exist deposit rates indexed to variables reflecting general economic conditions, there are - to our knowledge - no deposit rates related to the future risk profile of a bank.

Second, the model could also be extended to take into account - and assess the impact of - other possibilities than avoiding or minimizing the probability of a bank run to prevent the early liquidation of the investment project. For example, the bank could be given the opportunity of raising money from central banks and interbank markets in case a bank run occurs. Alternatively, the bank could buy an insurance in advance which would guarantee liquidity in case of depositor withdrawals. ${ }^{20}$

Third, as already indicated in the introduction, our model is clearly biased towards intransparency. Potentially beneficial effects of transparency are ignored. A first of these potentially beneficial effects is the role of transparency in disciplining banks. By forcing banks to disclose relevant information to the market - so the intention of various policy initiatives such as Pillar 3 of the new Basel Capital Accord-investors may be able to discipline the banks' risk taking behavior. In our model, this potentially beneficial role of transparency in disciplining banks is ruled out by assuming that the bank's risk profile is completely determined by exogenous factors. The bank in our model cannot choose its risk level. While this might appear a very strong assumption at first, the recent turmoil in financial markets showed that even banks that have not been directly exposed to the troubled markets suffered from the overall loss of

\footnotetext{
${ }^{20}$ The author thanks an anonymous refree for raising these points.
} 
confidence. Thus, there are circumstances that are out of the control of the banks and thus can affect also the most prudent institutions.

Another potentially beneficial effect of transparency is related to the fact that bank runs may also be efficient. On the one hand, bank runs may be efficient in that they serve as a mean to discipline banks. On the other hand, the liquidation of an inefficient bank also reduces the costs associated with an inefficient continuation of banks, e.g., costs due to the fact that banks have an incentive for gambling for resurrection when they are in trouble. Enhancing transparency may increase the probability that efficient bank runs indeed occur. Our model completely ignores the possibility of efficient bank runs. Bank runs in this setup are inefficient by assumption. ${ }^{21}$

Lastly, transparency in our setup is defined in the sense that information is disclosed to the market. It is important to emphasize that we do not analyze the case of information disclosed to the regulator. This is a further interesting topic to analyze.

\section{Conclusion}

This paper analyzes the optimal choice of a bank's transparency level in a simple model where the bank's investment portfolio is completely exposed to exogenous risk factors. Transparency is defined as the precision of a signal on the bank's state at the interim stage. At this interim stage, the bank might fall into a stress situation. Nevertheless, the bank's outlook is assumed to be favorable. We show that - in this setup - disclosing transparent information on the interim state of a bank might be harmful. In our model, enhancing transparency above a certain level may lead to the inefficient liquidation of a bank. The reason for this inefficient liquidation lies in the the payoff scheme of a standard deposit contract: this payoff scheme is limited above. Accordingly, depositors do not take into account possible future upside gains of the bank when deciding if they run the bank or not. Although assumed to be risk neutral, they act as if they were risk averse. Allowing for some degree of intransparency - or in some cases even complete intransparency - may keep depositors from running the bank and may thus avoid the inefficient liquidation of the bank.

The optimal degree of transparency in this model is determined so as to maximize the probability that the bank continues to operate until the end of the game. Given that the bank is completely exposed to exogenous risk factors that materialize in either

\footnotetext{
${ }^{21}$ See Chen and Hasan (2006) for a model with both efficient and inefficient bank runs.
} 
a good or a bad state at the interim stage, the bank faces a trade-off with respect to the transparency level: while in the case of the good state, transparency is preferred to intransparency, the contrary holds when the bad state occurs. In other words, the optimal transparency level varies with the parameters describing the bank's risk profile. The higher the probability that the bank is in a good state at the interim stage, the higher the optimal degree of transparency. However, the higher the bank's probability of remaining solvent in the end despite an unfavorable situation at the interim stage, the lower the optimal transparency level for a given relation between the probability of a good interim state and the (conditional) probability of remaining solvent in the end. An increase in these two probabilities increases the expected payoff from continuing compared to the expected payoff from liquidating the bank. The "continuing" outcome becomes more likely with a high transparency level in the good state and a low transparency level in the bad state at the interim stage.

Given the sometimes rather uncritical call for imposing transparency requirements on banks and on other financial institutions, this paper contributes to the discussion by emphasizing possible drawbacks of such policy initiatives. In doing so, it questions the unambiguous beneficial role of transparency in banking and calls for a more balanced discussion of this issue: "Transparency, like sunlight, needs to be looked at carefully." ${ }^{22}$

${ }^{22}$ The Economist, 2009. 


\section{References}

[1] Allen, F. and D. Gale (1998). Optimal Financial Crises. Journal of Finance 53(3), $1245-1284$

[2] Blum, J.M. (2002). Subordinated debt, market discipline, and banks' risk taking. Journal of Banking $\&$ Finance 26(7), 1427-1441.

[3] Boot, A.W.A., and A. Schmeits (2000). Market Discipline and Incentive Problems in Conglomerate Firms with Applications to Banking. Journal of Financial Intermediation 9(3), 240-273.

[4] Chen, Y. and I. Hasan (2006). The transparency of the banking system and the efficiency of information-based bank runs. Journal of Financial Intermediation $15(3), 307-331$.

[5] Chen, Y. and I. Hasan (2008). Why Do Bank Runs Look Like Panic? A New Explanation. Journal of Money, Credit and Banking 40(2-3), 535-546.

[6] Cordella, T. and E. L. Yeyati (1998). Public Disclosure and Bank Failures. IMF Staff Papers 45(1).

[7] De Grauwe, P. (2008). "Transparenz hilft nicht immer". Financial Times Deutschland, July 11.

[8] Diamond, D.W., and P.H. Dybvig (1983). Bank runs, deposit insurance, and liquidity. Journal of Political Economy 91(3), 401-419.

[9] Financial Stability Forum (2008). Report of the Financial Stability Forum on Enhancing Market and Institutional Resilience, April.

[10] Furman, J. and J.E. Stiglitz (1998). Economic Crises: Evidence and Insights from East Asia. Brookings Papers on Economic Activity 1998(2), 1-135.

[11] Healy, P.M. and K.G. Palepu (2001). Information asymmetry, corporate disclosure, and the capital markets: A review of the empirical disclosure literature. Journal of Accounting and Economics 31, 405-440. 
[12] Hyytinen, A. and T. Takalo (2002). Enhancing Bank Transparency: A ReAssessment. European Finance Review 6(3), 429-445.

[13] Hyytinen, A. and T. Takalo (2004). Preventing Systemic Crises through Bank Transparency. Economic Notes 33(2), 257-273.

[14] The Economist (2009). "Full disclosure", February 21.

[15] Verrecchia, R.E. (2001). Essays on disclosure. Journal of Accounting and Economics $32,97-180$. 


\section{Swiss National Bank Working Papers published since 2004:}

2004-1 Samuel Reynard: Financial Market Participation and the Apparent Instability of Money Demand

2004-2 Urs W. Birchler and Diana Hancock: What Does the Yield on Subordinated Bank Debt Measure?

2005-1 Hasan Bakhshi, Hashmat Khan and Barbara Rudolf: The Phillips curve under state-dependent pricing

2005-2 Andreas M. Fischer: On the Inadequacy of Newswire Reports for Empirical Research on Foreign Exchange Interventions

2006-1 Andreas M. Fischer: Measuring Income Elasticity for Swiss Money Demand: What do the Cantons say about Financial Innovation?

2006-2 Charlotte Christiansen and Angelo Ranaldo: Realized Bond-Stock Correlation: Macroeconomic Announcement Effects

2006-3 Martin Brown and Christian Zehnder: Credit Reporting, Relationship Banking, and Loan Repayment

2006-4 Hansjörg Lehmann and Michael Manz: The Exposure of Swiss Banks to Macroeconomic Shocks - an Empirical Investigation

2006-5 Katrin Assenmacher-Wesche and Stefan Gerlach: Money Growth, Output Gaps and Inflation at Low and High Frequency: Spectral Estimates for Switzerland

2006-6 Marlene Amstad and Andreas M. Fischer: Time-Varying Pass-Through from Import Prices to Consumer Prices: Evidence from an Event Study with Real-Time Data

2006-7 Samuel Reynard: Money and the Great Disinflation

2006-8 Urs W. Birchler and Matteo Facchinetti: Can bank supervisors rely on market data? A critical assessment from a Swiss perspective

2006-9 Petra Gerlach-Kristen: A Two-Pillar Phillips Curve for Switzerland

2006-10 Kevin J. Fox and Mathias Zurlinden: On Understanding Sources of Growth and Output Gaps for Switzerland

2006-11 Angelo Ranaldo: Intraday Market Dynamics Around Public Information Arrivals

2007-1 Andreas M. Fischer, Gulzina Isakova and Ulan Termechikov: Do FX traders in Bishkek have similar perceptions to their London colleagues? Survey evidence of market practitioners' views 
2007-2 Ibrahim Chowdhury and Andreas Schabert: Federal Reserve Policy viewed through a Money Supply Lens

2007-3 Angelo Ranaldo: Segmentation and Time-of-Day Patterns in Foreign Exchange Markets

2007-4 Jürg M. Blum: Why `Basel II’ May Need a Leverage Ratio Restriction

2007-5 Samuel Reynard: Maintaining Low Inflation: Money, Interest Rates, and Policy Stance

2007-6 Rina Rosenblatt-Wisch: Loss Aversion in Aggregate Macroeconomic Time Series

2007-7 Martin Brown, Maria Rueda Maurer, Tamara Pak and Nurlanbek Tynaev: Banking Sector Reform and Interest Rates in Transition Economies: Bank-Level Evidence from Kyrgyzstan

2007-8 Hans-Jürg Büttler: An Orthogonal Polynomial Approach to Estimate the Term Structure of Interest Rates

2007-9 Raphael Auer: The Colonial Origins Of Comparative Development: Comment. A Solution to the Settler Mortality Debate

2007-10 Franziska Bignasca and Enzo Rossi: Applying the Hirose-Kamada filter to Swiss data: Output gap and exchange rate pass-through estimates

2007-11 Angelo Ranaldo and Enzo Rossi: The reaction of asset markets to Swiss National Bank communication

2007-12 Lukas Burkhard and Andreas M. Fischer: Communicating Policy Options at the Zero Bound

2007-13 Katrin Assenmacher-Wesche, Stefan Gerlach, and Toshitaka Sekine: Monetary Factors and Inflation in Japan

2007-14 Jean-Marc Natal and Nicolas Stoffels: Globalization, markups and the natural rate of interest

2007-15 Martin Brown, Tullio Jappelli and Marco Pagano: Information Sharing and Credit: Firm-Level Evidence from Transition Countries

2007-16 Andreas M. Fischer, Matthias Lutz and Manuel Wälti: Who Prices Locally? Survey Evidence of Swiss Exporters

2007-17 Angelo Ranaldo and Paul Söderlind: Safe Haven Currencies 
2008-1 Martin Brown and Christian Zehnder: The Emergence of Information Sharing in Credit Markets

2008-2 Yvan Lengwiler and Carlos Lenz: Intelligible Factors for the Yield Curve

2008-3 Katrin Assenmacher-Wesche and M. Hashem Pesaran: Forecasting the Swiss Economy Using VECX* Models: An Exercise in Forecast Combination Across Models and Observation Windows

2008-4 Maria Clara Rueda Maurer: Foreign bank entry, institutional development and credit access: firm-level evidence from 22 transition countries

2008-5 Marlene Amstad and Andreas M. Fischer: Are Weekly Inflation Forecasts Informative?

2008-6 Raphael Auer and Thomas Chaney: Cost Pass Through in a Competitive Model of Pricing-to-Market

2008-7 Martin Brown, Armin Falk and Ernst Fehr: Competition and Relational Contracts: The Role of Unemployment as a Disciplinary Device

2008-8 Raphael Auer: The Colonial and Geographic Origins of Comparative Development

2008-9 Andreas M. Fischer and Angelo Ranaldo: Does FOMC News Increase Global FX Trading?

2008-10 Charlotte Christiansen and Angelo Ranaldo: Extreme Coexceedances in New EU Member States' Stock Markets

2008-11 Barbara Rudolf and Mathias Zurlinden: Measuring capital stocks and capital services in Switzerland

2008-12 Philip Sauré: How to Use Industrial Policy to Sustain Trade Agreements

2008-13 Thomas Bolli and Mathias Zurlinden: Measuring growth of labour quality and the quality-adjusted unemployment rate in Switzerland

2008-14 Samuel Reynard: What Drives the Swiss Franc?

2008-15 Daniel Kaufmann: Price-Setting Behaviour in Switzerland - Evidence from CPI Micro Data

2008-16 Katrin Assenmacher-Wesche and Stefan Gerlach: Financial Structure and the Impact of Monetary Policy on Asset Prices

2008-17 Ernst Fehr, Martin Brown and Christian Zehnder: On Reputation: A Microfoundation of Contract Enforcement and Price Rigidity 
2008-18 Raphael Auer and Andreas M. Fischer: The Effect of Low-Wage Import Competition on U.S. Inflationary Pressure

2008-19 Christian Beer, Steven Ongena and Marcel Peter: Borrowing in Foreign Currency: Austrian Households as Carry Traders

2009-1 Thomas Bolli and Mathias Zurlinden: Measurement of labor quality growth caused by unobservable characteristics

2009-2 Martin Brown, Steven Ongena and Pinar Yeșin: Foreign Currency Borrowing by Small Firms

2009-3 Matteo Bonato, Massimiliano Caporin and Angelo Ranaldo: Forecasting realized (co)variances with a block structure Wishart autoregressive model

2009-4 Paul Söderlind: Inflation Risk Premia and Survey Evidence on Macroeconomic Uncertainty

2009-5 Christian Hott: Explaining House Price Fluctuations

2009-6 Sarah M. Lein and Eva Köberl: Capacity Utilisation, Constraints and Price Adjustments under the Microscope

2009-7 Philipp Haene and Andy Sturm: Optimal Central Counterparty Risk Management

2009-8 Christian Hott: Banks and Real Estate Prices

2009-9 Terhi Jokipii and Alistair Milne: Bank Capital Buffer and Risk Adjustment Decisions

2009-10 Philip Sauré: Bounded Love of Variety and Patterns of Trade

2009-11 Nicole Allenspach: Banking and Transparency: Is More Information Always Better? 
Swiss National Bank Working Papers are also available at www.snb.ch, section Publications/Research Subscriptions or individual issues can be ordered at Swiss National Bank, Fraumünsterstrasse 8, CH-8022 Zurich, fax+41 4463181 14, E-mail library@snb.ch 